Ann. Génét. Sél. anim., I973, 5 (2), 267-274.

\title{
A GENETIC BASE FOR ESTIMATING THE GENETIC TRANSMITTING ABILITY OF DAIRY BULLS IN POPULATIONS UNDERGOING GENETIC CHANGE
}

\author{
F. N. DICKINSON \\ Acting Leader, \\ Animal Improvement Programs Laboratory, \\ Animal Physiology and Genetics Institute, \\ Agricultural Research Service, United States Department of Agriculture, \\ Beltsville, Maryland 20705 - U.S. A.
}

\section{SUMMARY}

The three major problems encountered in the genetic evaluation of dairy bulls in today's dynamic dairy cattle populations are discussed. These are : a continuing increase in the average genetic merit of the population, an average rate of genetic increase that fluctuates over time, and the formation of genetic sub-populations. Neither a fixed genetic base nor a moving genetic base (presently used by U.S. D. A.) is suitable over a long term basis for calculating genetic evaluations which are unbiased over time and acceptable to people in the field. A new concept, a Stepwise Genetic Base, is described which will enable unbiased comparisons of bulls evaluated at different times and will enable all genetic evaluations to be expressed relative to the population's average genetic merit at any point in time. U. S. D. A. will adopt this new concept in revised sire summary procedures and most other countries could use the same procedure.

\section{IN'TRODUC'TION}

Some form of a herdmate comparison is used in virtually all countries that are evaluating the genetic transmitting ability of dairy bulls. Most, if not all, of these procedures are based on the assumption that there is no genetic trend in the dairy cattle population. This assumption was reasonable when adopted, because there had been little genetic progress from sire summary methods used before. However, the success of the herdmate comparison method is apparent to all involved with

(1) Invited report Presented at the $23 \mathrm{rd}$ Annual Study Meeting of the European Association for Animal Production, Commission of Animal, Genetics, Verona, Italy, october 8, 1972. 
the genetic improvement of dairy cattle. In fact, the effectiveness of the herdmate comparison has invalidated the basic anderlying assumption of nog enetic progress.

A major problem at present is how to increase the rate of genetic progress in cattle populations that are becoming continually more difficult to evaluate because of this increase in genetic merit. Practically all countries are faced with essentially the same difficulties inevaluating dairy bulls for genetic merit. Therefore, there should be a general set of principles for overcoming these difficulties.

\section{PROBLEMS OF GENETIC TREND COMMON TO ALI, COUNTRIES}

Probably the most common and most basic problem with which we are faced today is attempting to estimate genetic transmitting abilities in populations in which the average genetic merit is increasing. Of course, the rates of increase may differ considerably from country to country. It is almost certain that all countries having organized programs for genetic improvement of dairy cattle are showing at least some increase in genetic merit at the present time.

This problem is compounded even more by the fact that the rate of genetic progress in each country probably changes from time to time because of causes over which most of us have very little control, for example : (I) by chance, several outstanding bulls may be identified in rapid succession followed by a period where fewer outstanding bulls are found; $(2)$ the use of outstanding bulls may be tenpered from time to time by the heavy use of bulls with popular names or other popular appeal but which do not have truly superior genotypes, and (3) errors that are due to sampling variation in the daughters, or from other causes, may result in occasional serious overestimates or underestimates of genetic transmitting ability of individual bulls.

To accentuate the problem to an even greater degree most of us no longer deal with genetically uniform and homogenous populations. We are actually dealing with a group of sub-populations that vary in average genetic merit and in the rate of genetic change. For example, in the United States we have many sub-populations that have developed because of the following :

I. Not all of the artificial insemination (AI) organizations are fortunate enough to have bulls of the same genetic superiority. Therefore, dairymen in certain regions have easier access to the best bulls than do those in others.

2. Some regions contain higher concentrations of registered or purebred cows than others. On the average, the registered herds probably have higher genetic merit than do the nonregistered herds although the superiority varies from region to region and many nonregistered herds are genetically superior to many registered ones.

3. Milk-pricing policies vary considerably in different parts of the country causing dairymen to place different emphasis on the different yield traits. In some parts, the highest profit can be made from producing the greatest amount of milk regardless of composition (within reasonable limits). In other parts, especially in the Midwest where many herds produce primarily manufacturing milk, dairymen can maximize profits by maximizing the amount of butterfat produced. 
4. Dairymen in some areas of the country are more highly business oriented. This trend generally causes heavier selection for total economic value, meaning primarily yield and a few other traits affecting the economic worth of each animal.

5. There are vast differences throughout the country in the proportion of herds taking advantage of the dairy record keeping programs (D.H.I.A.). Cows in D. H. I. A. herds outproduce the nontested cows by approximately $40 \mathrm{p}$. Ioo in milk production. This higher production is certainly due to an important degree to the genetic superiority in these herds. Such superiority results from heavier use of the genetically superior AI bulls and more effective selection and culling practices within the herds. Some of the above influences have probably caused the formation of genetic sub-populations in other countries besides the United States.

\section{THE IMPOR'TANCE OF THE GENETIC BASE}

These three problems, a continual rise in average genetic merit, fluctuations in the average rate of genetic increase over time, and the formation of sub-populations, make accurate sire summaries, which can be compared over a long time, an extraordinarily difficult problem. This situation demands that we use sophisticated statistical, genetic, and computing techniques.

In my previous report I gave a brief overview of two alternative sire summary methods that should aleviate these problems. It appears to those of us at U. S. D. A. that either of the methods - the Direct Comparison Method or the U. S. D. A. Modified Contemporary Comparison Method, should overcome these problems and provide accurate sire summaries on most bulls. However, my previous report intentionally omitted one major point - the genetic base to which sire summaries are calculated.

To make meaningful rankings of bulls over a long period of time, one must be able to compare estimates of the transmitting ability of the same bull summarized at different times, of different bulls summarized at the same time and of different bulls summarized at different times. In other words, one should be able to compare estimates of transmitting ability over a long period of time on the same basis. At the present time, this cannot be done with the U. S. D. A.-D. H. I. A. Sire Summaries and this same deficiency is probably true in many of the countries represented a tthis meeting. However, I would like to suggest a genetic base procedure whereby this can be done. I believe this procedure would be easily understood by people who use sire summaries in the field and who are not highly trained in animal genetics.

In the simplest case there are actually only two types of genetic bases, fixed and moving. For reasons explained here, neither of these types of base is adequate under present conditions.

\section{FIXED GENETIC BASE}

The use of a fixed base under the conditions existing in most of our dairy cattle populations would result in the situation that is shown in figure $I$. It is true that, with a fixed base, comparisons can be made among bulls summarized at widely 
different times. It should probably be mentioned as a side-light that comparisons among bulls evaluated at different times will generally not be as accurate for ranking as will comparisons among bulls evaluated at the same time no matter what genetic base is used. If the sire summaries were to be used strictly by scientists, then the use of a fixed base over a long period of time would be satisfactory. However, most of the people who use this information in the field in all of our countries are not trained as scientists. In the U.S. these people still tend to look on Predicted Differences as a point-estimate of each bull's transmitting ability, rather than considering them as merely a method for determining differences among bulls. When a dairyman is asked what kind of bulls he uses, he seldom replies: "I use only those that rank one, two, three. " More often he will reply: "A bull must have a Predicted Difference for milk of at least + I ooo pounds $(454 \mathrm{~kg})$ " or he will say: "I will use a bull with a Predicted Difference as low as +800 pounds $(363 \mathrm{~kg})$ if the bull improves these particular conformation traits in which my herd needs improvement. "The use of a fixed base over a long time interval would cause confusion among such dairymen because bulls that are well above breed average today would be only breed average or even below breed average bulls in the future. Yet their Predicted Differences would still be as high as originally. This can be seen in figure I where a bull with a

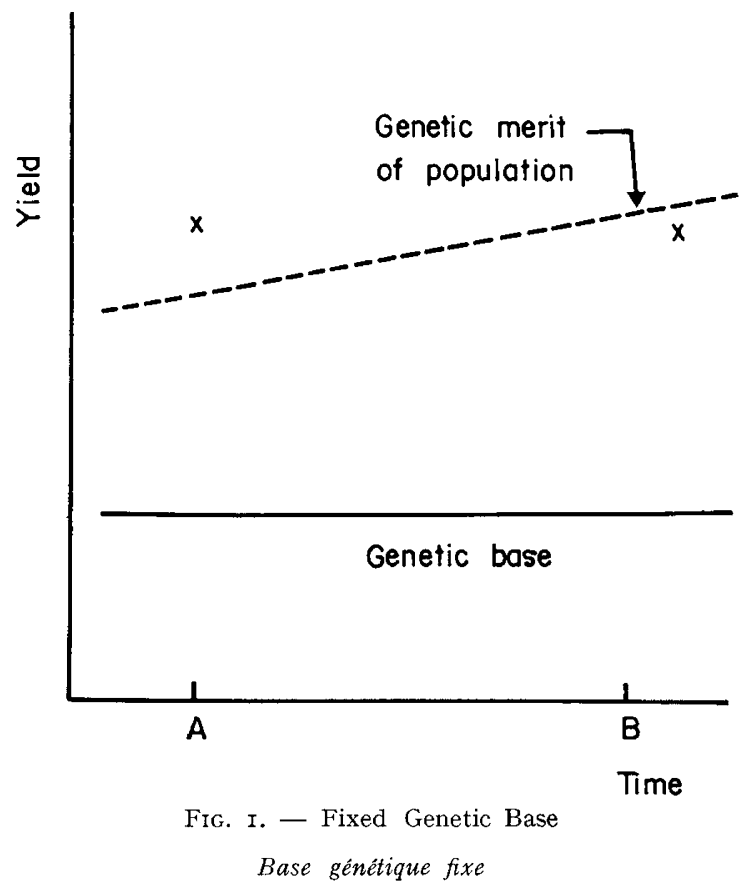

genetic transmitting ability at level $\mathrm{X}$ is above the population average at point $\mathrm{A}$ in time, but is below the population average at point B in time. Many dairymen would probably fail to make an appropriate adjustment in the level of PD required for their herd even though bulls of higher genetic merit would continually become available. After an extended period of time, PD's would increase to a very high level 
and the base would have to be adjusted. It would cause much confusion and loss of confidence if after let's say Io years or more, a tremendous change was suddenly made in the base. This would mean that evaluations of existing bulls might be lowered as much as $400 \mathrm{~kg}$ or more. It would be very dificult for many dairymen to adjust their thinking to such a drastic change in the base after so long a period of time.

\section{MOVING GENETIC BASE}

The use of a moving genetic base would result in the situation shown in figure 2 . This is actually what the U.S. D. A. uses at the present time. The genetic base is changed every year based on the latest updating of breed averages from the records we have received for use in the sire summaries. This means that sire summaries calculated one year cannot be compared without bias to those calculated in other years. Older bulls have higher evaluations than they should when compared to bulls evaluated more recently in time. This can be seen in figure 2 . One bull whose Predicted Difference is shown by the letter $\mathrm{X}$ was progeny-tested at point $\mathrm{A}$ in time and another (bull $\mathrm{Y}$ ) was tested at point $\mathrm{B}$ in time. Both have the same Predicted Difference.

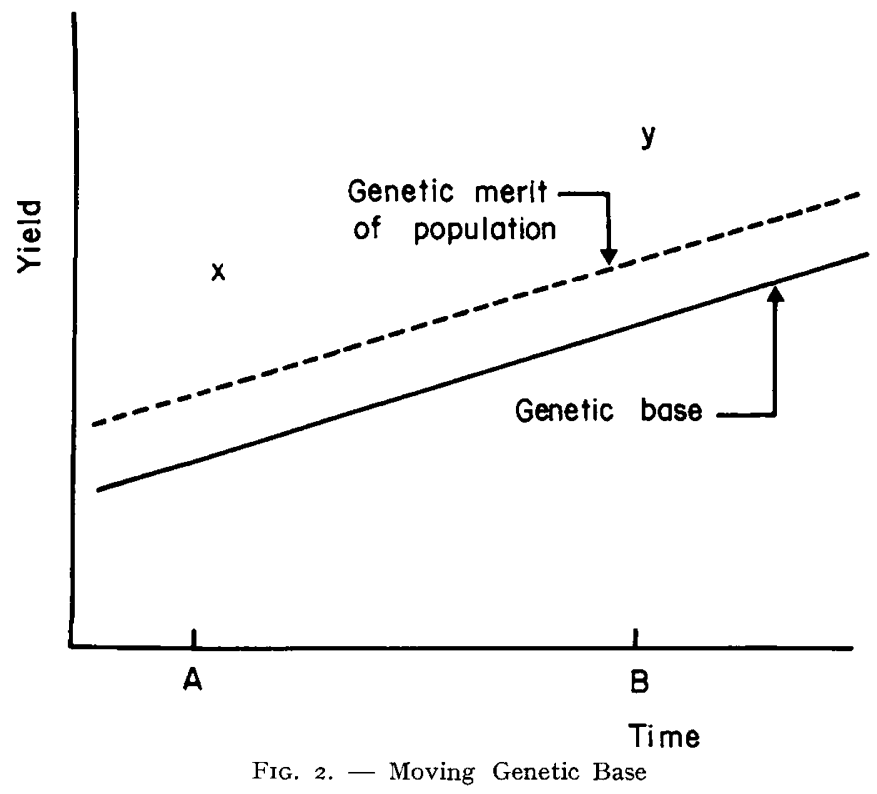

Base génétique en évolution

However, the bull tested at point B in time (bull $\mathrm{Y}$ ) is genetically superior to the other bull (bull $\mathrm{X}$ ) because his transmitting ability is expressed relative to a population of higher genetic merit. This situation causes artificial insemination organizations and dairymen to continue to use older bulls which may actually be genetically inferior to many younger bulls. The moving genetic base also causes repeated sire summaries 
on a bull to continually decrease or " erode " over time as additional daughters are added. Dairymen tend to lose confidence in the summaries when this happens and those who do not understand the summaries very well continually wonder what is wrong when bulls keep dropping in genetic merit. Also, we believe that it is almost impossible to use a moving genetic base and continually keep all summaries in perspective so that they can be compared over long periods of time. The only way this could be done would be to ; I) adjust all Predicted Differences of herdmate sires every time a sire summary is run, 2) resummarize all bulls for which anyone might wish information (i.e., for pedigrees) no matter how old, and, 3) discard all previous summaries on all bulls. It would be very costly to carry out these procedures and they would result in a waste of our already limited resources.

\section{STEPWISE GENETIC BASE}

Therefore, it appears that the most realistic approach to this problem, and the one which we intend to adopt as soon as it can be added to our sire summary system, is a combination of fixed and moving genetic'bases such as shown in figure 3 . We have labelled this a Stepwise Genetic Base.

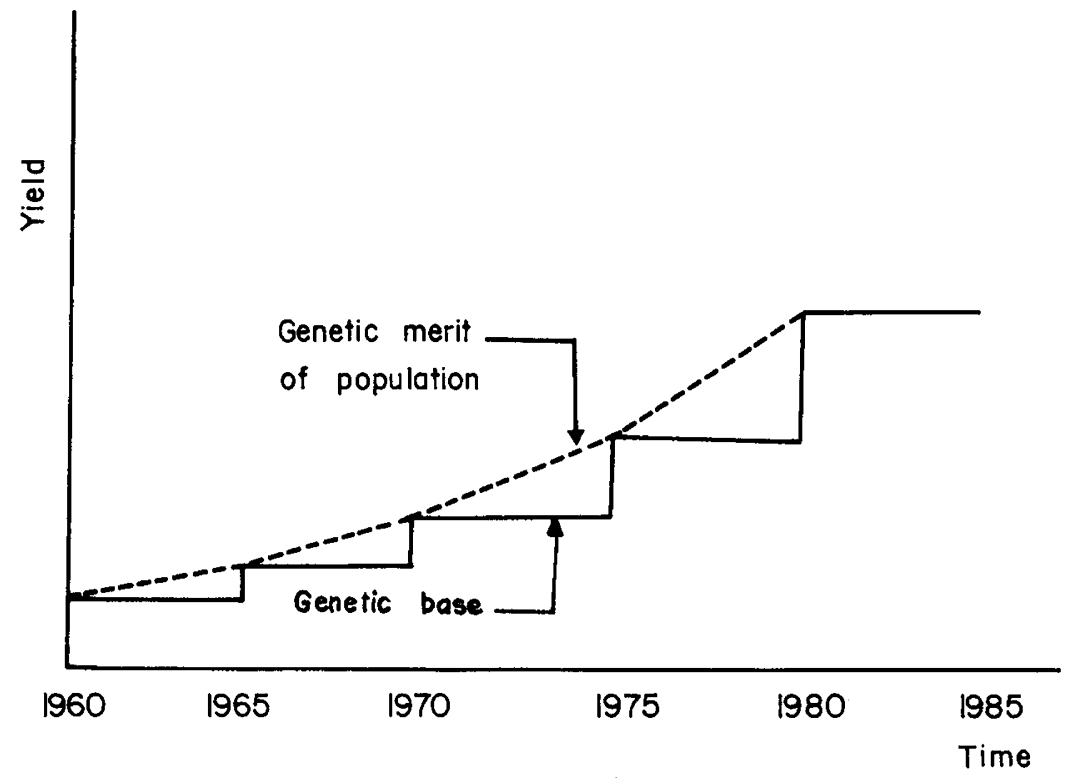

FIG. 3. - Stepwise Genetic Base proposed for use in genetic evaluation of dairy cattle

Base génétique en escalier proposée pour l'évaluation du progrès génétique des bovins laitiers

This procedure would permit all summaries to be adjusted to the genetic base presently in use and would permit unbiased comparisons of sire summaries which have been calculated at widely different points in time. The genetic base to which all sire summaries are calculated would be changed periodically, possibly every 3 to 5 years. Changes at 5 year intervals are shown in figure 3 . These changes would be 
announced in advance and the notification of dairymen and others using the summaries could be carried out before the change so that they would be expecting it and would understand the reasons behind it. When this procedure is adopted, all summaries could be calculated to the present genetic base. Then, summaries for bulls from previous years could be adjusted to bases that would apply to those previous time periods before they are published. The latter procedure would have great public relations benefits in our country. It would eliminate the drastic drop that will likely occur in the Predicted Differences of many of the early AI bulls if their summaries are published relative to the present base. Sire summaries in the years $197 \mathrm{I}-75$ would all be calculated to the genetic base 1970 . Then in 1976 through I980, all summaries would be calculated to the genetic base 1975 . When the genetic base is changed all sire summaries that have been calculated previously could be adjusted to the new genetic base simply by subtracting the amount of change which had occurred between I970 and 9I75. For example, assuming that the genetic base changed by $4001 \mathrm{bs}$ (I8I kg), then, bulls that had been evaluated $+\mathrm{I}$ ooo $1 \mathrm{bs}(+454 \mathrm{~kg})$ at the 1970 base would be adjusted to a PD of $+600 \mathrm{lbs}(+273 \mathrm{~kg})$ at the 1975 base. Summaries for bulls used primarily in previous years could be adjusted to a previous genetic base in a similar manner.

In order to make this system workable the present abbreviation for Predicted Difference, "PD " would have to be changed to include the genetic base to which each PD was calculated. Therefore, Predicted Differences calculated to the I970 base would be labeled " $\mathrm{PD}_{70}$ " and $\mathrm{PD}$ 's calculated to the 1975 base would be designated " $\mathrm{PD}_{75}$ ". In the same way, PD's for bulls used in previous years could be expressed to bases $\mathrm{PD}_{60}$ or $\mathrm{PD}_{65}$.

This procedure would have another advantage in the use of sire summaries for pedigree work or for other historical purposes. Most bulls eventually cease to be summarized either because they do not produce any new daughters or because some arbitrary cutoff is designated in the interest of economy of running sire summaries. Under this system when a bull is no longer being summarized he would have a permanent Predicted Difference which would contain the genetic base to which it was calculated. This final PD would go into permanent records and could be used in the future for comparisons with bulls summarized at other times by adjusting the Predicted Difference to whatever common base was being used to compare bulls at that time. This should make pedigree evaluations far more accurate and useful than they are at the present time, since those presently being used may contain serious biases because of genetic trend.

As might be expected, the Stepwise Genetic Base will not solve all the problems associated with genetic trend. As with the moving and fixed bases, a single stepwise base may not be entirely appropriate for all genetic sub-populations within a country. There is still the relatively minor problem of genetic trend within the base periods causing some inaccuracies; however, this will be much less than with our present procedures. In addition, it will be necessary to determine the amount of genetic progress that takes place from one base period to the next so that the genetic base can be changed by a realistic amount. Some additional research input into the sire summary program will be required. In spite of these relatively minor problems, the Stepwise Genetic Base would result in a major overall increase in accuracy when compared to our present procedures. 
Needless to say, the adoption of such a revolutionary change would require a massive educational effort by those of us involved in dairy cattle genetics work; however, I believe that there are many advantages to this system. If a strong educational effort were made before its adoption, then it would be readily accepted by those utilizing sire summaries in our country. In fact, it might be a strong tool to build much greater confidence in sire summaries than we now have among many users in the field. The additional cost in computing time would not be great even under our situation where upwards of 20000 bulls are evaluated each year and more than $\mathrm{I} 2000$ ooo lactation records are used during each sire summary run. It is hoped that adoption of this procedure would eliminate one of the most serious problems in the present U. S. D. A.-D. H. I. A. Sire Summaries and would result in a major increase in accuracy and usefulness of genetic evaluations of dairy cattle.

Reçu pour publication en novembre 1972.

\section{RÉSUMÉ}

\section{LE NIVEAU GÉNÉTIQUE DE RÉFÉRENCE DANS L'ESTIMATION \\ DE LA VALEUR GÉNÉTIQUE DES TAUREAUX DES POPULATIONS DE BOVINS LAITIERS EN PROGRÈS GÉNÉTIQUE}

Les trois problèmes majeurs rencontrés pour l'évaluation du niveau génétique des taureaux dans les populations actuelles de bovins laitiers en pleine évolution sont discutés. Il s'agit de l'élévation continuelle du niveau génétique moyen de la population, des fluctuations au cours du temps de cette augmentation, et de la formation de sous-populations génétiques. Un niveau génétique de référence fixé ou variable (utilisé actuellement par 1'U. S. D. A.) ne conviennent ni l'un ni l'autre à long terme au calcul d'index qui ne soient pas biaisés dans le temps et qui soient acceptables par les praticiens. Un nouveau concept, le niveau génétique de référence en escalier, est décrit : il permettra la comparaison sans biais de taureaux testés à différentes époques et permettra à toutes les évaluations génétiques d'être exprimées par rapport au niveau génétique moyen de la population, à n'importe quelle époque.

L'U. S. D. A. adoptera ce nouveau concept dans ses nouvelles méthodes d'indexation des taureaux : la plupart des autres pays pourrait se servir du même principe.

\section{ZUSAMMENFASSUNG}

\section{EINE GENETISCHE BASIS BEI DER ZUCHTWERTSCHÄTZUNG FÜR MILCH VON STIEREN IN POPULATIONEN MIT GENETISCHEM TREND}

Die drei Hauptprobleme, die bei der Zuchtwertschätzung für Milch bei Stieren in den heutigen dynamischen Milchviehpopulationen entstehen, werden diskutiert. Dies sind : Eine kontinuierliche Zunahme des durchschnittlichen genetischen Niveaus der Population, eine durchschnittliche genetische Zuwachsrate, die mit der Zeit schwankt und die Bildung genetischer SubPopulationen. Weder einer feste noch eine bewegliche (gegenwärtig im U.S.D. A. angewandt) genetische Basis ist über eine lange Zeitdauer geeignet für die Berechnung von Zuchtwerten, die über längere Zeiten frei von systematischen Fehlern und daher für Fachleute annehmbar sind. Ein neues Konzept, eine stufenweise genetische Basis, wird beschrieben, das erlauben wird, ungestörte Vergleiche von Stieren durchzuführen, deren Zuchtwert zu verschiedenen Zeiten geschätzt wird und auch erlauben wird, alle geschätzten Zuchtwerte jederzeit relativ zum genetischen Populationsmittel anzugeben. Das U.S. D. A. wird dieses neue Konzept in den revidiretene Stieren-Prüfungsverfahren annehmen und die meisten andern Länder könnten dasselbe Verfahren verwenden. 